\title{
Fouling characteristics and cleaning strategies of NF membranes for the advanced treatment of antibiotic production wastewater
}

\author{
Jianxing Wang ${ }^{1,2} \cdot$ Kun $^{\mathrm{Li}^{1,2}} \cdot$ Dawei Yu ${ }^{1,2} \cdot$ Junya Zhang ${ }^{1,2} \cdot$ Yuansong Wei ${ }^{1,2}$
}

Received: 30 June 2015 / Accepted: 9 September 2015 / Published online: 18 September 2015

(C) Springer-Verlag Berlin Heidelberg 2015

\begin{abstract}
The nanofiltration (NF) membrane fouling characteristics and cleaning strategies were investigated through a laboratory-scale NF fouling test treating membrane bioreactor (MBR) effluent and MBR-granular activated carbon (GAC) effluent of an antibiotic production wastewater by DK and NF90 membranes, respectively. Results showed that organic fouling is the main NF membrane fouling for treating both the MBR effluent and MBR-GAC effluent. Soluble microbial by-product (SMP)-like and aromatic protein-like substances were the dominant components in the foulants, whereas humic-like substances had little contribution to the NF fouling. The fouling of DK was more severe than that of NF90. However, foulants respond by $\mathrm{UV}_{254}$ were more easily to foul NF90 membrane. It could get satisfactory effect using combined cleaning of acid ( $\mathrm{HCl}, \mathrm{pH}$ 2.0 2.5) and alkali $(\mathrm{NaOH}+0.3 \mathrm{wt} \% \mathrm{NaDS}, \mathrm{pH} 10.0 \sim 10.5)$. The favorable cleaning strategy is "acid+alkali" for treating MBR-GAC effluent, while it is "alkali+acid" for treating MBR effluent.
\end{abstract}

Keywords Nanofiltration · Fouling · Cleaning · Antibiotic production wastewater $\cdot$ MBR $\cdot$ MBR-GAC

Responsible editor: Bingcai Pan

Yuansong Wei

yswei@rcees.ac.cn

1 State Key Joint Laboratory of Environmental Simulation and Pollution Control, Research Center for Eco-Environmental Sciences, Chinese Academy of Sciences, Beijing 100085, China

2 Beijing Key Laboratory of Industrial Wastewater Treatment and Reuse, Research Center for Eco-Environmental Sciences, Chinese Academy of Sciences, Beijing 100085, China

\section{Introduction}

As the water resources in various regions and countries are expected to face unprecedented pressures in the coming decades, wastewater is considered to be an alternative water resource which can decrease the demands for fresh water (Bunani et al. 2013). In China, the pharmaceutical industry has experienced rapid development and becomes one of the major industries discharging industrial wastewater and pollutions. It is reported that the amount of discharged wastewater from the pharmaceutical industry in China was 539.59 million tons in 2013 (National Bureau of Statistic, China, 2014). This kind of wastewater is hard to meet the reuse or discharge standards by conventional treatment processes because of high concentrations of recalcitration pollutions (Chelliapan et al. 2006; Xing and Sun 2009). Therefore, there are great needs to make advanced treatment for the aim of reusing pharmaceutical wastewater.

Among many advanced treatment processes, nanofiltration (NF) is a fast-growing technology in the advanced treatment of municipal and industrial wastewater for reuse (Chon et al. 2011; Aouni et al. 2009; Ellouze et al. 2012). In our previous study, NF was used for the advanced treatment of antibiotic production wastewater, and the result showed that the NF permeate could meet China's water quality standard requirements for industrial use (GB21903-2008) (Wang et al. 2015). However, membrane fouling is still a major obstacle for practical application of NF in the treatment of wastewater as other pressure-driven membrane processes (Chon et al. 2013).

To solve the fouling problem of NF membrane, a lot of researches have been done on the fouling characteristics, control methods, and chemical cleaning strategies. According to the literature, the characteristics of the NF membrane fouling are determined by feed water composition (Xu et al. 2006). For example, Xu et al. (Xu et al. 2006) reported that the major 
components of foulants were polysaccharides, organic sulfonic acids, silicate colloids, $\mathrm{Si}, \mathrm{Cu}, \mathrm{Fe}, \mathrm{Zn}$, and $\mathrm{Ca}$ when treating the secondary effluent of a local municipal wastewater using NF in Denver, CO. However, Azais et al. (Azais et al. 2014) demonstrated that polysaccharides and humic acids were the major compounds adsorbed on the NF membrane of the municipal WWTP effluent collected in south of France. Due to the difference of membrane fouling characteristics, the cleaning strategies would be changed (Al-Amoudi et al. 2008; Mo et al. 2010). Though there were many studies on membrane fouling of NF, the results were quite different. Moreover, many studies focus on simulated wastewater (Mahlangu et al. 2014), the studies on membrane foulant identification and cleaning strategy are rather scarce in real wastewater, especially in industrial wastewater.

The formation of the fouling layer could also be influenced by NF membrane characteristic. Nghiem et al. 2008 studied the fouling of humic acid of three different NF membranes and found that pore blocking was prominent for the larger pore size TFC-SR2 membrane, but the cake-enhanced concentration polarization effect appeared to be more significant for the tighter NF-270 and NF-90 membranes. In addition, many studies showed that employing adequate pretreatment ahead the membrane process could alleviate membrane fouling (Kumar et al. 2006; Al-Amoudi and Lovitt 2007), such as coagulation (Al-Amoudi and Lovitt 2007), UF (Luo et al. 2011), activated carbon filtration (BenitoAlcazar et al. 2010), and $\mathrm{O}_{3}$ oxidation (Flyborg et al. 2010). Our previous studies used two different pretreatment technologies of MBR and MBR-GAC before NF for treating antibiotic production wastewater, and results showed that both of them could get excellent water qualities (Wang et al. 2014a; Wang et al. 2014b; Wang et al. 2015). However, the membrane fouling should be further studied for the practical application.

In this study, the fouling characteristics and cleaning strategies of two commercially available NF membranes (DK and NF90) by two pretreatment strategies, MBR and MBR-GAC, were investigated and compared in the advanced treatment of antibiotic production wastewater. The foulants on the membrane surface were desorbed by different cleaners and identified. Moreover, scanning electron microscope (SEM), atomic force microscopy (AFM), and attenuated total reflectancefourier transform infrared spectroscopy (ATR-FTIR) were employed to analyze the different membrane surfaces and cleaning effects.

\section{Materials and methods}

\section{Wastewater}

The raw wastewater was the effluent of the anaerobic from a wastewater treatment station of a pharmaceutical company producing spiramycin in Wuxi (China). Before NF treatment, it was pretreated by MBR and MBR-GAC firstly, and then, the $\mathrm{pH}$ values of the two effluents were adjusted to about 6.0 according to our previous study (Wang et al. 2014a). The characteristics of the MBR and MBR-GAC effluents were shown in Table 1.

\section{Experimental setup and membrane}

As shown in Fig. 1, NF fouling tests were performed by using a cross-flow flat-sheet membrane test unit (SEPA CF II, GE Osmonics). Both permeate and retentate were circulated back to the feed reservoir. Fouling tests were conducted at pressure of 1.0 MPa and crossflow velocity of $1.0 \mathrm{~L} / \mathrm{min}$ at $25^{\circ} \mathrm{C}$. Each fouling test was carried out for $45 \mathrm{~h}$.

Two flat-sheet NF membranes, DK and NF90, which were provided by GE Osmonics and Dow/Filmtec, were employed to compare the fouling of different membranes. Table 2 lists the specification of the membranes provided by the manufacturers and literatures.

After fouling test, the fouled membrane was divided into six parts. Five of these parts were soaked with deionized water (DI water), acid ( $\mathrm{HCl}, \mathrm{pH} 2.0 \sim 2.5)$, alkali $(\mathrm{NaOH}+0.3 \mathrm{wt} \%$ NaDS, pH 10.0 10.5), acid+alkali (soaked with acid firstly and then with alkali), and alkali+acid (soaked with alkali firstly and then with acid) for $24 \mathrm{~h}$, respectively. The membranes and desorbed solutions were further analyzed to investigate the fouling characteristics and cleaning strategies.

\section{Analysis}

Total organic carbon (TOC) was determined by a TOC-VCPH (Shinadzu, Japan). $\mathrm{UV}_{254}$ was measured by an ultraviolet and visible spectrophotometer (Spectrum Lab 752sp, Lengquang

Table 1 Characteristics of the MBR and MBR-GAC effluents

\begin{tabular}{|c|c|c|c|c|c|c|c|c|c|c|}
\hline Item & $\mathrm{UV}_{254}\left(\mathrm{~cm}^{-1}\right)$ & $\begin{array}{l}\text { TOC } \\
(\mathrm{mg} / \mathrm{L})\end{array}$ & $\begin{array}{l}\text { TDS } \\
(\mathrm{mg} / \mathrm{L})\end{array}$ & $\begin{array}{l}\mathrm{Ca}^{2+} \\
(\mathrm{mg} / \mathrm{L})\end{array}$ & $\begin{array}{l}\mathrm{K}^{+} \\
(\mathrm{mg} / \mathrm{L})\end{array}$ & $\begin{array}{l}\mathrm{Mg}^{2+} \\
(\mathrm{mg} / \mathrm{L})\end{array}$ & $\begin{array}{l}\mathrm{Na}^{+} \\
(\mathrm{mg} / \mathrm{L})\end{array}$ & $\begin{array}{l}\mathrm{Cl}^{-} \\
(\mathrm{mg} / \mathrm{L})\end{array}$ & $\begin{array}{l}\mathrm{NO}_{3}{ }^{-} \\
(\mathrm{mg} / \mathrm{L})\end{array}$ & $\begin{array}{l}\mathrm{SO}_{4}{ }^{2-} \\
(\mathrm{mg} / \mathrm{L})\end{array}$ \\
\hline MBR & $1.52 \pm 0.00$ & $106.07 \pm 0.39$ & $3715 \pm 100$ & $248.90 \pm 5.48$ & $115.33 \pm 3.97$ & $24.20 \pm 0.16$ & $1012.35 \pm 1.82$ & $1928.82 \pm 5.76$ & $357.72 \pm 0.46$ & $42.30 \pm 0.24$ \\
\hline MBR-GAC & $0.36 \pm 0.19$ & $38.26 \pm 8.57$ & $3650 \pm 170$ & $235.02 \pm 6.65$ & $138.81 \pm 2.94$ & $28.65 \pm 0.81$ & $1173.64 \pm 0.77$ & $2139.25 \pm 107.54$ & $359.91 \pm 0.70$ & $100.31 \pm 0.73$ \\
\hline
\end{tabular}




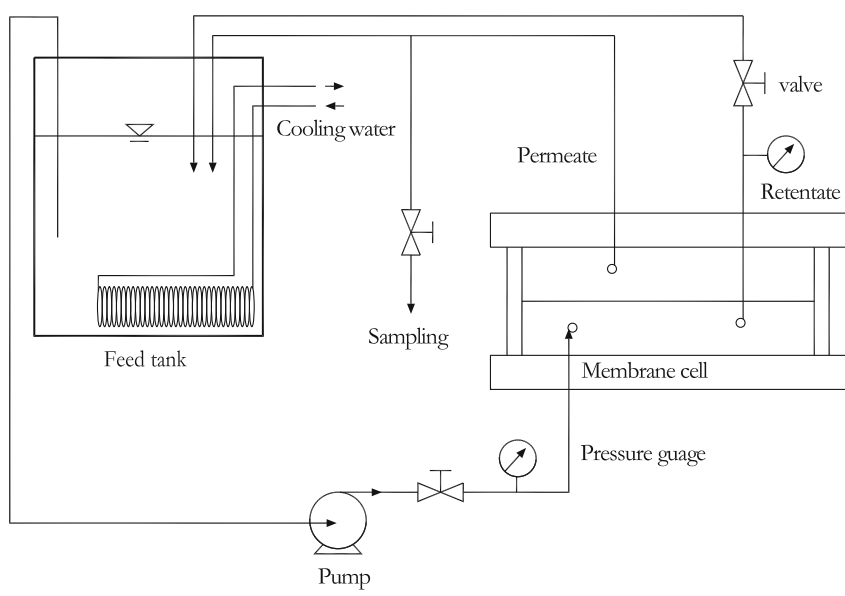

Fig. 1 Schematic diagram of the cross-flow laboratory-scale membrane test unit

Tech, China). Total dissolved solids (TDS) was measured with a conductivity/TDS meter (HI4321, Hanna, Italy). pH was measured with a WTW Multi 3420 apparatus (WTW, Germany). The contents of $\mathrm{Ca}^{2+}, \mathrm{Na}^{+}, \mathrm{K}^{+}$, and $\mathrm{Mg}^{2+}$ were analyzed by an inductively coupled plasma optical emission spectroscopy (Optima 2100 DV, Perkin Elmer, USA). The anions $\left(\mathrm{Cl}^{-}, \mathrm{NO}_{3}{ }^{-}, \mathrm{NO}_{2}{ }^{-}, \mathrm{SO}_{4}{ }^{2-}\right.$, and $\left.\mathrm{PO}_{4}{ }^{3-}\right)$ were determined using an ion chromatography (ICS-1000, Dionex, USA).

A fluorescence spectrophotometer (F-7000, Hitachi, Japan) was used to investigate major components and the complexity of organic matter that were contained in the NF feeds and desorbed solutions.

SEM (S-3000N, Hitachi, Japan) analysis was carried out to observe the surfaces of virgin and fouled membranes. All samples were freeze-dried for $24 \mathrm{~h}$.

Membrane surface roughness was determined using AFM (NanoScope IIIa, Digital Instruments, USA). Imaging was performed in tapping mode on an area of $2 \mu \mathrm{m} \times 2 \mu \mathrm{m}$. Each sample was measured three times.
ATR-FTIR was performed using a Fourier transform infrared spectrometer (Nicolet 8700, Thermo Electron Corporation, USA) with a resolution of $4 \mathrm{~cm}^{-1}$ in the range $400-4000 \mathrm{~cm}^{-1}$ to obtain information about the functional groups of the membrane surfaces.

\section{Results and discussion}

\section{Membrane performance}

Figure 2 shows the flux decline of these two NF membranes treating the MBR and MBR-GAC effluent. As shown in Fig. 2, the permeate flux declined sharply based on time, with approximately $60 \%$ flux decline in the end. This result showed that both the membranes suffered severe fouling over the duration of the experiment. One possible reason of the severe fouling is that the membrane used in this study was a flat-sheet membrane. Previous researches (Rohricht et al. 2009) indicated that the flat-sheet membrane could enlarge the fouling level compared to other types of membrane, such as the spiral-wound membrane, which could analyze the membrane fouling easily. This is also the reason of why there was no obvious difference between the two effluents. At the initial stage, the flux decline of NF treating MBR-GAC effluent was less than that treating MBR effluent, which illustrated that adding GAC after MBR could alleviate membrane fouling. This phenomenon was not apparent due to the rapid fouling with filtration time of the flat-sheet membrane. However, the severe membrane fouling is helpful for us to study its characteristics in the advanced treatment of antibiotic production wastewater. Moreover, Fig. 2 also shows that for treating the same effluent, the flux of DK membrane declined more than NF90 membrane, which indicated that DK membrane suffered more membrane fouling than that of NF90.

Table 2 Characteristics of different membranes used in this study

\begin{tabular}{lll}
\hline Parameter & DK & NF90 \\
\hline Manufacturer & Osmonics & DOW/Filmtec \\
Material & Polymide & Polymide \\
Surface area, cm ${ }^{2}$ & 139 & 139 \\
MWCO, Da & $150-300$ (Sjoman et al. 2007) & 200 (Bunani et al. 2013) \\
Pore size, nm & 0.40 (Bowen and Welfoot 2002) & 0.31 (Simon et al. 2013) \\
Roughness, nm & 11.186 & 48.016 \\
Surface zeta potential at $\mathrm{pH} 4, \mathrm{mV}$ & 7.4 & 24.6 \\
Max temperature, ${ }^{\circ} \mathrm{C}$ & 50 & 45 \\
Max operating pressure, bar & 41.4 & 41 \\
pH range & $3-9$ & $3-10$ \\
Rejection & $98 \%$ & $>97 \%$ \\
Test conditions & $\mathrm{MgSO}_{4}, 2000 \mathrm{ppm}, 7.6$ bar, $15 \%$ recovery, $25^{\circ} \mathrm{C}$ & $\mathrm{MgSO}_{4}, 2000$ ppm, 4.8 bar, $15 \%$ recovery, $25^{\circ} \mathrm{C}$ \\
\hline
\end{tabular}


Fig. 2 Changes of NF membrane flux decline with operating time

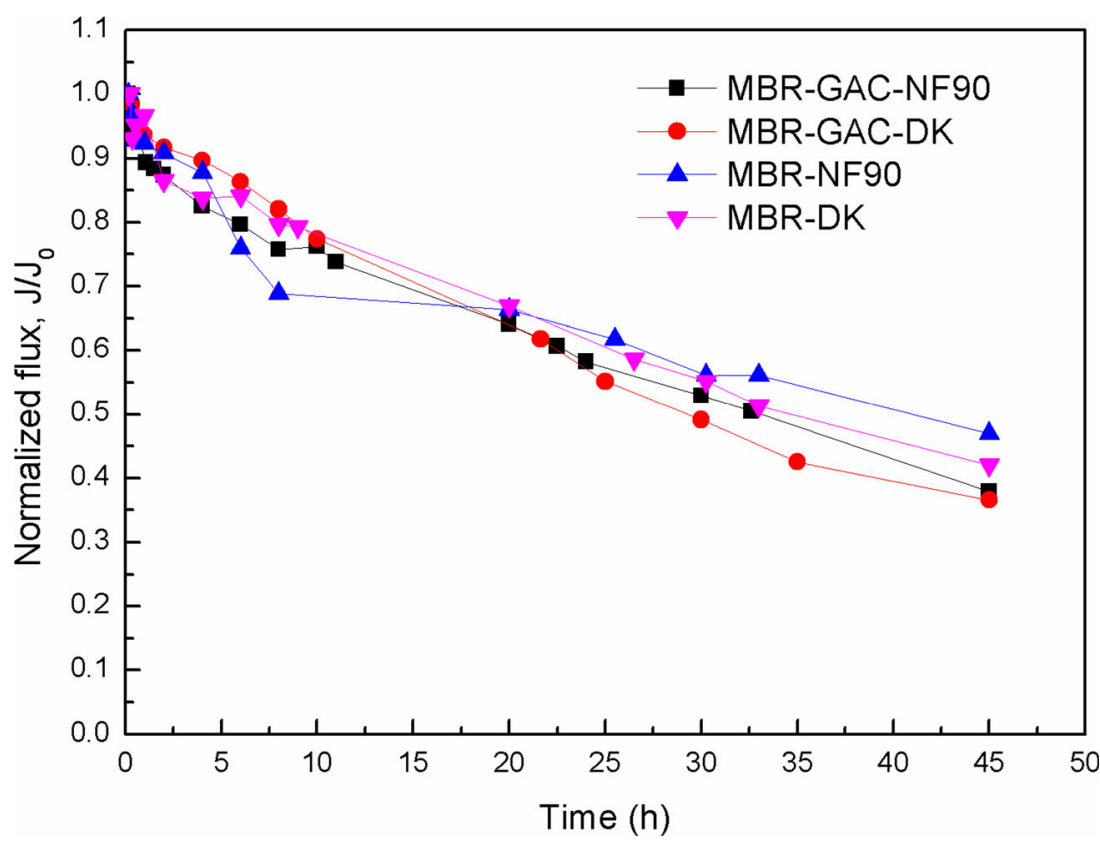

\section{Membrane morphological analysis}

SEM and AFM analyses were carried out to observe the surfaces of virgin and fouled membranes in treating MBR and MBR-GAC effluents using different NF membranes. Results were shown in Figs. 3 and 4.

As the SEM photos in Fig. 3, the surfaces of virgin membrane of NF90 and DK membranes were rather clean and symmetrical. By contrast, it was obvious that the membrane surface was fouled seriously after fouling test. A cake layer was formed by the foulants attached to the membrane surface for the all tests. The AFM photos in Fig. 4 were consistent with the SEM results that the cake layers were obvious of the fouling membranes.

The roughnesses of different membranes were also measured through AFM analysis. Result shows that the mean roughnesses of the virgin and fouled membrane changed apparently. For NF90, the mean roughnesses of the virgin membrane, fouled membrane treating MBR-GAC effluent, and the fouled membrane treating MBR effluent were 48.016, 26.357,
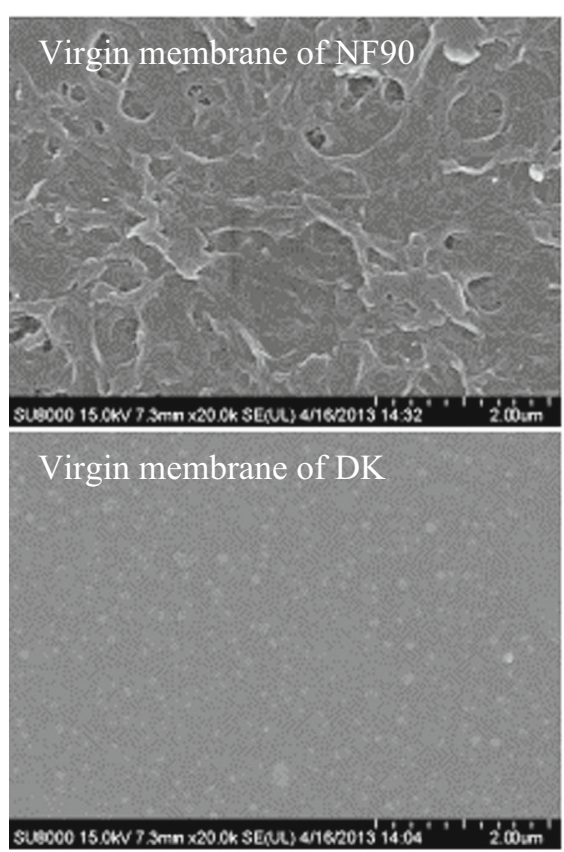
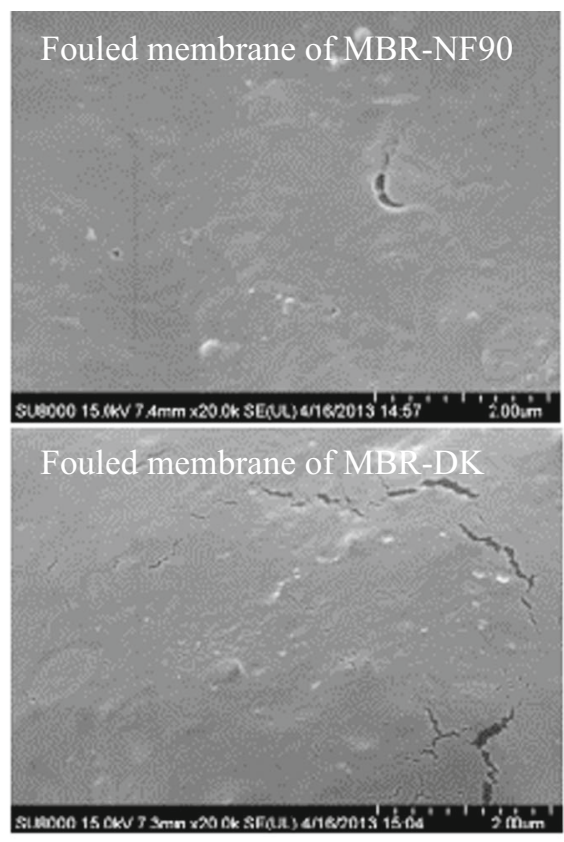

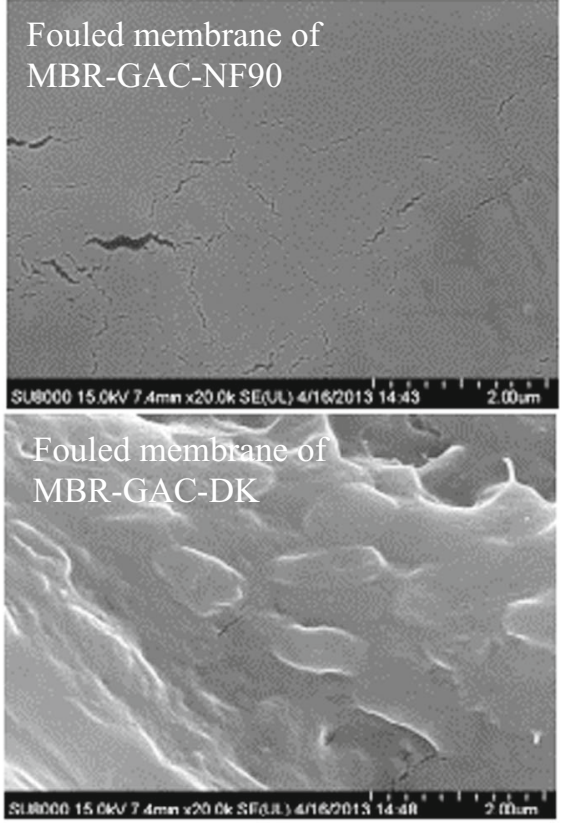

Fig. 3 Comparison of SEM photos of virgin and fouled NF membranes 
and $40.710 \mathrm{~nm}$, respectively. However, changes of roughnesses of DK membranes were quite different, i.e., the mean roughnesses were $11.186,23.710$, and $34.638 \mathrm{~nm}$, respectively. It illustrated that the roughness of NF90 membrane was
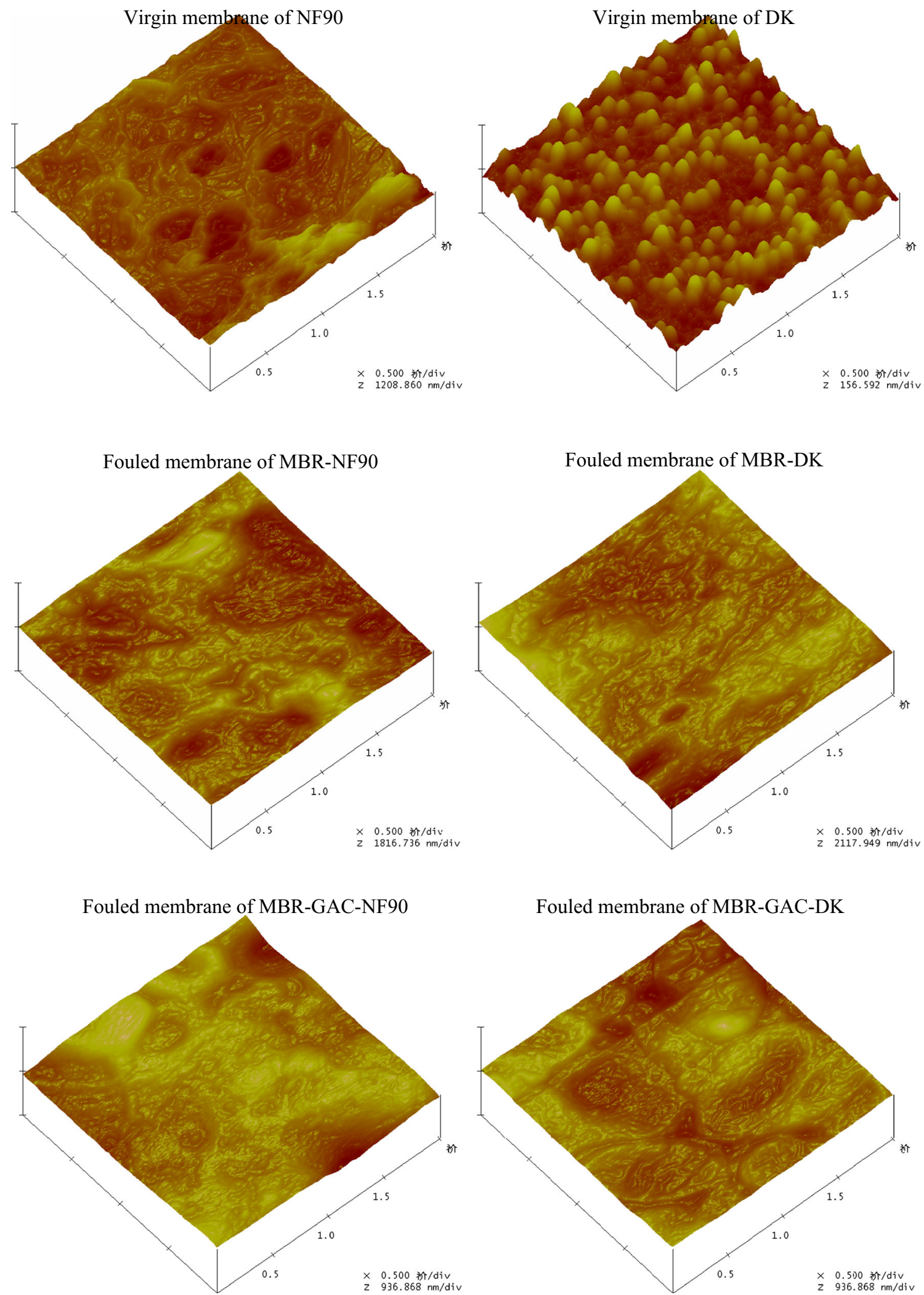

Fig. 4 Comparison of AFM photos of virgin and fouled NF membranes 
decreased after fouling, while the roughness of DK membrane was increased. This is mainly because the roughnesses of the virgin membranes of NF90 and DK were rather different, for the virgin DK membrane was smooth (the mean roughness is $11.186 \mathrm{~nm}$ ) while virgin NF90 membrane is relatively rough (the mean roughness is $48.016 \mathrm{~nm}$ ). Xu et al. (Xu et al. 2006) showed that the "valley" on the rough NF membrane surfaces was filled by foulants, which resulted in a smoother surface morphology. For the smooth NF membrane, the foulants had no crevices to fill in and built up on the surface resulting in an increase in surface roughness.

\section{Identification of membrane foulant and cleaning strategies}

\section{Characterization of the foulant desorbed by different cleaning strategies}

Analysis of foulant desorbed by different cleaners could help to identify the foulant composition and concentration on the fouling membrane (Xiao et al. 2012). In this study, the organics and inorganic ions of the desorption solutions were analyzed, respectively. The extent of organics was determined by $\mathrm{UV}_{254}$ and TOC measurements along the different cleaning strategies described above (Fig. 5). From Fig. 5, we can see that higher concentrations of $\mathrm{UV}_{254}$ and TOC were detected desorbed by alkali cleaning, acid+alkali cleaning, and alkali+ acid cleaning in all the tests. According to the literature, alkaline cleaning is always used to remove adsorbed organics (AlAmoudi and Lovitt 2007). Therefore, we inferred that organics were a main factor of membrane fouling in advanced treatment of antibiotic production wastewater by NF membrane.

The results of inorganic ions analysis showed that none of the inorganic ions (including $\mathrm{Ca}^{2+}, \mathrm{Mg}^{2+}, \mathrm{SO}_{4}{ }^{2-}$, which existed in the NF feeds) were found in each desorption solution. This result illustrated that no inorganic foulant was found in this study. Therefore, the analysis of foulant demonstrated that organics fouling was the dominant membrane fouling in advanced-treating antibiotic production wastewater by $\mathrm{NF}$ membrane under test conditions.

Figure 5 also shows that the TOC concentrations in the desorption solutions of DK membrane $(83.84 \mathrm{mg} / \mathrm{L}$ in treating MBR-GAC effluent and $83.95 \mathrm{mg} / \mathrm{L}$ in treating MBR effluent, respectively) were higher than those of NF90 membrane $(62.49 \mathrm{mg} / \mathrm{L}$ in treating MBR-GAC effluent and $62.19 \mathrm{mg} / \mathrm{L}$ in treating MBR effluent, respectively). As the organics fouling was the dominant membrane fouling, we concluded that the fouling of DK membrane was more severe than NF90 membrane in treating both the MBR-GAC effluent and MBR effluent. The difference of the membrane fouling between DK and NF90 membranes might be due to the membrane characteristic such as membrane pore size and surface roughness. Nghiem and Hawkes (Nghiem and Hawkes 2007) reported that fouling was more severe for the larger-pore-sized membrane compared to smaller-pore-sized membrane when removed pharmaceutically active compounds by three different membranes, which was consistent with results of our study. In addition, Fig. 5 shows that $\mathrm{UV}_{254}$ in the desorption solution of NF90 membrane was higher than that of DK membrane, which declared that foulants respond by $\mathrm{UV}_{254}$ were more easily to foul NF90 membrane. Literature showed that $\mathrm{UV}_{254}$ usually represents the aromatic organics (Benitez et al. 2011). This result might be due to the reaction between typical organics and different membrane surfaces, which should be further studied.

Furthermore, on the basis of TOC and $\mathrm{UV}_{254}$ concentrations in the desorption solutions in Fig. 5, the maximum amount of organics was desorbed through acid+alkali of treating MBR-GAC effluent, while maximum amount of organics was desorbed through alkali+acid of treating MBR effluent. This result showed that the favorable cleaning strategies is acid+alkali when treating MBR-GAC effluent, while it is alkali+acid when treating MBR effluent. The reason of this phenomenon might be due to the different compositions of the two effluents. As shown in Table 1, the inorganic ions of the two effluents were in the same level, whereas the organic concentrations were apparent different. This led to different inorganic/organic compositions of the two effluents, i.e., $\mathrm{Ca}^{2+} / \mathrm{TOC}$ ratio at 2.35 for MBR effluent and 6.14 for MBR-GAC effluent, respectively. Kappel et al. (Kappel et al. 2014) showed that change of $\mathrm{Ca}^{2+} / \mathrm{TOC}$ ratio could induce different membrane fouling characteristics. Moreover, Xiao et al. (Xiao et al. 2012) demonstrated that $\mathrm{HCl}$ solution could remove the substance of aromatic protein, while $\mathrm{NaOH}$ solution could remove both aromatic protein and other organics such as SMP-like substance. Therefore, the difference of inorganic/organic ratios in the two effluents might lead to different compositions of membrane foulant, which further needs the different cleaning strategies.

As the dominant foulant of NF membrane was organics, we analyzed the composition of the organics which were desorbed from the fouled membrane surface by 3D-EEMs. The 3D-EEMs is a collection of a series of emission spectra over a range of excitation wavelengths that can be used to identify the complex mixtures (Wang et al. 2009, 2015). According to Chen's (Chen et al. 2003) study, the 3D-EEM spectral divided the EEM into five regions, including humic acid-like, fulvic acid-like, tyrosine-like, tryptophan-like, and soluble microbial by-product-like organics, respectively. The results of 3D-EEMs of the organics in desorption solution were shown in Fig. 6.

As shown in Fig. 6, strong humic-like fluorescence of peak A with maximum peaks at Ex/Em of 325/400 nm was found both in the MBR-GAC effluent and MBR effluent. The concentrations of humic-like substance in MBR effluent were 
much higher than that of MBR-GAC effluent, which was corresponding to the organic concentration in Table 1. However, two new peaks, i.e., peaks B and C, which were corresponding to soluble microbial by-product (SMP)-like and aromatic protein-like substances according to Chen's (Chen et al. 2003) study, appeared in solutions desorbed from the fouled
Fig. 5 TOC and $U^{254}$ concentration in the desorption solution
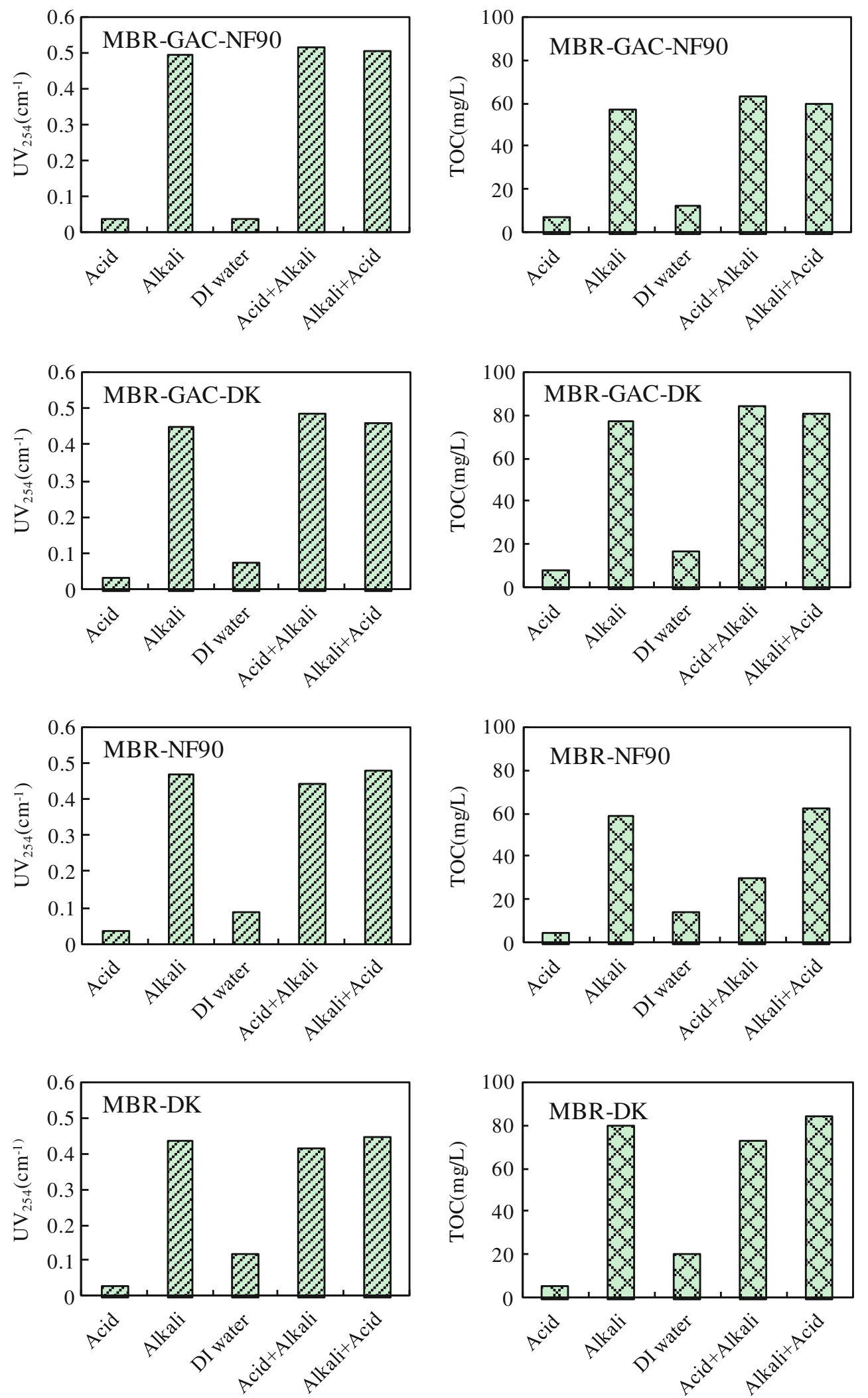

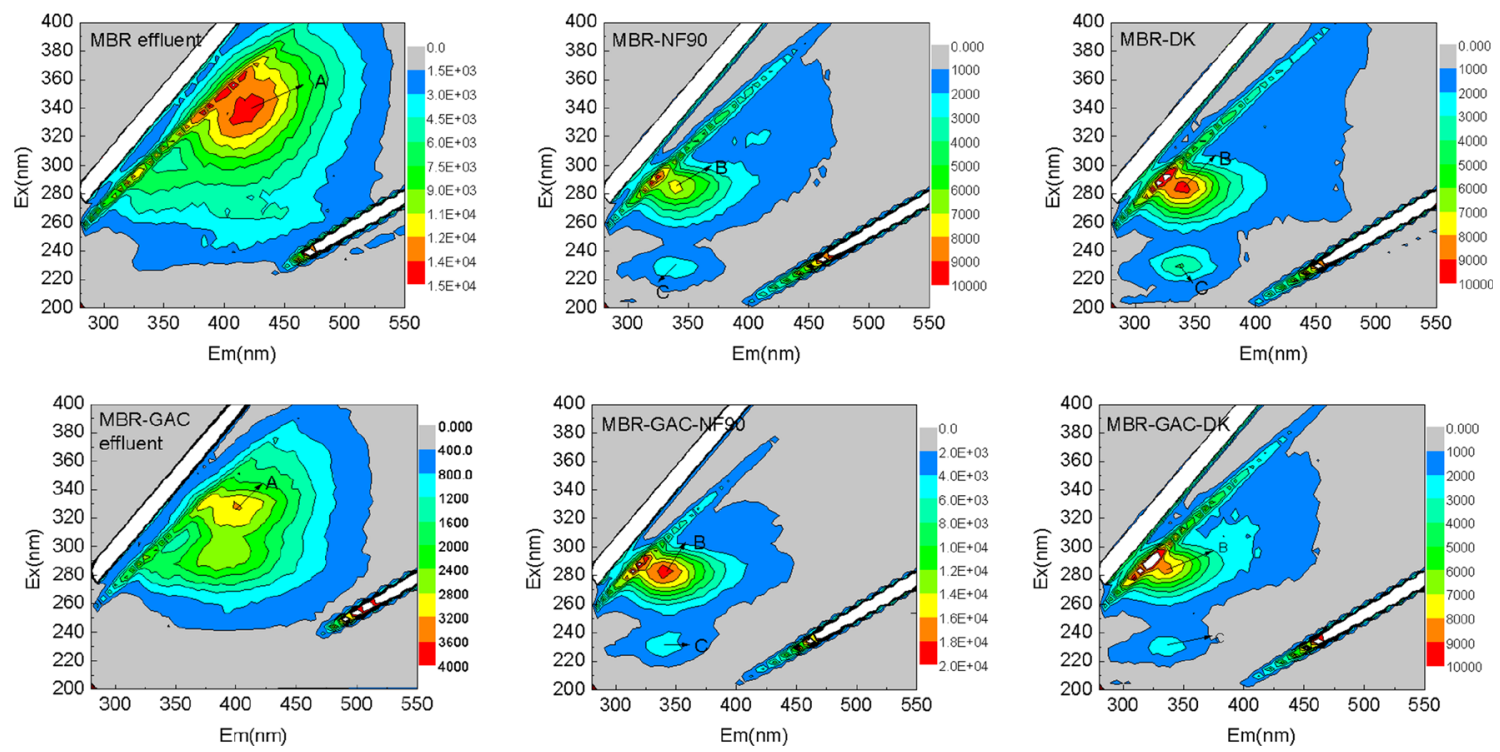

Fig. 6 3D-EEMs in the desorption solution

membranes. Nevertheless, no peak of humic-like fluorescence was found in the desorption solutions. The results of 3DEEMs demonstrated that SMP-like and aromatic protein-like substances were the dominant components in the foulants, whereas humic-like substances had little contribution to the NF fouling. Chon et al. (Chon et al. 2011) showed that polysaccharides and amino groups played a major role in fouling formation of NF system when treating municipal wastewater. Zazouli et al. (Zazouli et al. 2010) found that humic acid exhibited less membrane fouling than that of alginate. These foundings in the literatures could perfectly support our results in this study.

\section{Attenuated total reflectance-fourier transform infrared spectroscopy analysis of different membranes}

Attenuated total reflectance-fourier transform infrared spectroscopy (ATR-FTIR) provides a convenient and effective way to determine the composition of thin-film composite membranes. It has been employed to analyze the chemical changes of the membrane surface before and after chemical cleaning (Wang et al. 2010; Evans and Bird 2006). The virgin, fouled, and cleaned membranes have been investigated by ATR-FTIR spectral analysis, and results are presented in Fig. 7.

As shown in Fig. 7, the ATR-FTIR spectral showed a similarly changed trend of the virgin, fouled, and cleaned membranes in different tests. The spectra of the DK and NF90 virgin membranes were similar to the specific FTIR absorbance peaks typical for polyamide membranes (Mo et al. 2010). However, after fouled for $45 \mathrm{~h}$, the peaks of fouled membranes decreased in both the absorbance intensity and peak quantity, suggesting that the membranes were severely fouled. Some new peaks were found on the surfaces of fouled membranes. As far as the fouled DK membrane treating MBR effluent is concerned, $\mathrm{N}-\mathrm{H}$ stretching of amides were found in the range of $3500-3100 \mathrm{~cm}^{-1}$ and $850-750 \mathrm{~cm}^{-1}$ (Chon et al. 2013). Two bands were observed near 1635 and $1539 \mathrm{~cm}^{-1}$, these bands correspond to the amide I and amide II bands of an amide structure, which would be indicative of proteins (Howe et al. 2002). The absorption bands observed near 1069 and $1231 \mathrm{~cm}^{-1}$ were assigned to the $\mathrm{C}-\mathrm{O}$ bond of ethers or carboxylic acid, probably a polysaccharide (Cho et al. 1998). Absorption in this region indicated the presence of polysaccharide-like/polysaccharide (SMP-like) substances. The peak at $680-880 \mathrm{~cm}^{-1}$ is probably due to an aromatic carbon (Howe et al. 2002). The peak near $2900 \mathrm{~cm}^{-1}$ was due to oversubtraction of $\mathrm{C}-\mathrm{H}$ stretching band. Based on the ATRFTIR spectra of the fouled membranes, we can conclude that the main foulants deposited on the membrane surface were protein and polysaccharide, which were consistent with the results of 3D-EEMs. For the ATR-FTIR spectra of cleaned membrane, it was apparent that there were significant similarities in the spectra obtained for the cleaned membrane with the virgin membrane, which demonstrated that it could get satisfactory effect combined acid and alkali cleaning.

\section{Conclusions}

Organic fouling is the main membrane fouling in the advanced treatment of antibiotic production wastewater by NF membrane. Soluble microbial by-product (SMP)-like and aromatic protein-like substances were the dominant components in the foulants, whereas humic-like substances had little contribution to the NF membrane fouling. The fouling of DK membrane was more severe than that of NF90 membrane. Foulants that respond by $\mathrm{UV}_{254}$ were more easily to foul 
Fig. 7 ATR-FTIR spectra of different NF membranes

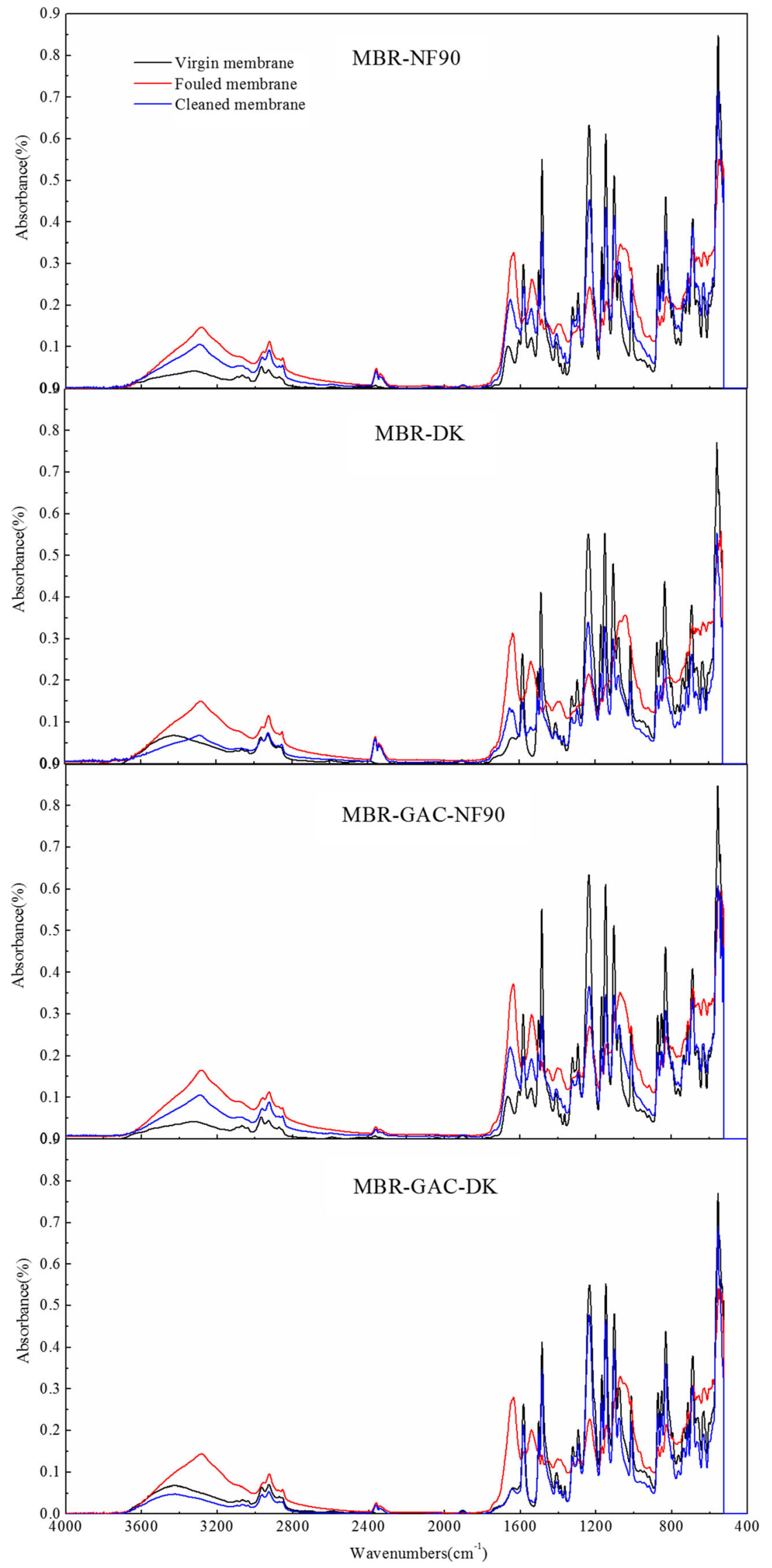


NF90 membrane. The favorable cleaning strategy is "acid+ alkali" for treating MBR-GAC effluent, while it is "alkali+ acid" for treating MBR effluent.

Acknowledgments Financial support provided by the National Major Science \& Technology Projects for Water Pollution Control and Management (No. 2012ZX07203-002 and 2015ZX07203-005), National Science Foundation for Post-doctoral Scientists of China (No. 2015 M571140), and National High Technology Research and Development Program of China (No. 2009AA063901) are gratefully acknowledged.

\section{References}

Al-Amoudi A, Lovitt RW (2007) Fouling strategies and the cleaning system of NF membranes and factors affecting cleaning efficiency. J Membr Sci 303(1-2):6-28

Al-Amoudi A, Williams P, Al-Hobaib AS, Lovitt RW (2008) Cleaning results of new and fouled nanofiltration membrane characterized by contact angle, updated DSPM, flux and salts rejection. Appl Surf Sci 254(13):3983-3992

Aouni A, Fersi C, Ali M, Dhahbi M (2009) Treatment of textile wastewater by a hybrid electrocoagulation/nanofiltration process. J Hazard Mater 168(2-3):868-874

Azais A, Mendret J, Gassara S, Petit E, Deratani A, Brosillon S (2014) Nanofiltration for wastewater reuse: counteractive effects of fouling and matrice on the rejection of pharmaceutical active compounds. Sep Purif Technol 133:313-327

Benitez FJ, Acero JL, Real FJ, Roldan G, Rodriguez E (2011) Ultrafiltration and nanofiltration membranes applied to the removal of the pharmaceuticals amoxicillin, naproxen, metoprolol and phenacetin from water. J Chem Technol Biotechnol 86(6):858-866

Benito-Alcazar C, Vincent-Vela MC, Gozalvez-Zafrilla JM, Lora-Garcia J (2010) Study of different pretreatments for reverse osmosis reclamation of a petrochemical secondary effluent. J Hazard Mater 178(1-3):883-889

Bowen WR, Welfoot JS (2002) Modelling of membrane nanofiltrationpore size distribution effects. Chem Eng Sci 57(8):1393-1407

Bunani S, Yorukoglu E, Sert G, Yuksel U, Yuksel M, Kabay N (2013) Application of nanofiltration for reuse of municipal wastewater and quality analysis of product water. Desalination 315(SI):33-36

Chelliapan S, Wilby T, Sallis PJ (2006) Performance of an up-flow anaerobic stage reactor (UASR) in the treatment of pharmaceutical wastewater containing macrolide antibiotics. Water Res 40(3): 507-516

Chen W, Westerhoff P, Leenheer JA, Booksh K (2003) Fluorescence excitation - emission matrix regional integration to quantify spectra for dissolved organic matter. Environ Sci Technol 37(24):57015710

Cho JW, Amy G, Pellegrino J, Yoon YM (1998) Characterization of clean and natural organic matter (NOM) fouled NF and UF membranes, and foulants characterization. Desalination 118(1-3):101-108

Chon K, Sarp S, Lee S, Lee JH, Lopez-Ramirez JA, Cho J (2011) Evaluation of a membrane bioreactor and nanofiltration for municipal wastewater reclamation: trace contaminant control and fouling mitigation. Desalination 272(1-3):128-134

Chon K, Cho J, Shon HK (2013) Fouling characteristics of a membrane bioreactor and nanofiltration hybrid system for municipal wastewater reclamation. Bioresour Technol 130:239-247

Ellouze E, Tahri N, Ben Amar R (2012) Enhancement of textile wastewater treatment process using nanofiltration. Desalination 286:16-23
Evans PJ, Bird MR (2006) Solute-membrane fouling interactions during the ultrafiltration of black tea liquor. Food Bioprod Process 84(C4): 292-301

Flyborg L, Bjorlenius B, Persson KM (2010) Can treated municipal wastewater be reused after ozonation and nanofiltration? Results from a pilot study of pharmaceutical removal in Henriksdal WWTP, Sweden. Water Sci Technol 61(5):1113-1120

Howe KJ, Ishida KP, Clark MM (2002) Use of ATR/FTIR spectrometry to study fouling of microfiltration membranes by natural waters. Desalination 147(1-3SI):251-255

Kappel C, Kemperman A, Temmink H, Zwijnenburg A, Rijnaarts H, Nijmeijer K (2014) Impacts of NF concentrate recirculation on membrane performance in an integrated MBR and NF membrane process for wastewater treatment. J Membr Sci 453:359-368

Kumar M, Adham SS, Pearce WR (2006) Investigation of seawater reverse osmosis fouling and its relationship to pretreatment type. Environ Sci Technol 40(6):2037-2044

Luo J, Ding L, Qi B, Jaffrin MY, Wan Y (2011) A two-stage ultrafiltration and nanofiltration process for recycling dairy wastewater. Bioresour Technol 102(16):7437-7442

Mahlangu TO, Hoek E, Mamba BB, Verliefde A (2014) Influence of organic, colloidal and combined fouling on $\mathrm{NF}$ rejection of $\mathrm{NaCl}$ and carbamazepine: role of solute-foulant-membrane interactions and cake-enhanced concentration polarisation. J Membr Sci 471: $35-46$

Mo YH, Chen JH, Xue WC, Huang X (2010) Chemical cleaning of nanofiltration membrane filtrating the effluent from a membrane bioreactor. Sep Purif Technol 75(3):407-414

National Bureau of Statistic China. (2014). Industrial wastewater discharge and treatment. Available. http:/www.stats.gov.cn/ztjc/ztsj/ hjtjzl/2013/201412/t20141216_654131.html

Nghiem LD, Hawkes S (2007) Effects of membrane fouling on the nanofiltration of pharmaceutically active compounds (PhACs): mechanisms and role of membrane pore size. Sep Purif Technol 57(1):176-184

Nghiem LD, Vogel D, Khan S (2008) Characterising humic acid fouling of nanofiltration membranes using bisphenol $\mathrm{A}$ as a molecular indicator. Water Res 42(15):4049-4058

Rohricht M, Krisam J, Weise U, Kraus UR, During RA (2009) Elimination of carbamazepine, diclofenac and naproxen from treated wastewater by nanofiltration. Clean Soil Air Water 37(8):638641

Simon A, McDonald JA, Khan SJ, Price WE, Nghiem LD (2013) Effects of caustic cleaning on pore size of nanofiltration membranes and their rejection of trace organic chemicals. J Membr Sci 447:153-162

Sjoman E, Manttari M, Nystrom M, Koivikko H, Heikkila H (2007) Separation of xylose from glucose by nanofiltration from concentrated monosaccharide solutions. J Membr Sci 292(1-2):106-115

Wang JX, Li K, Wei YS, Cheng YT, Wei DB, Li MY (2015) Performance and fate of organics in a pilot MBR-NF for treating antibiotic production wastewater with recycling NF concentrate. Chemosphere 121:92-100

Wang JX, Wei YS, Cheng YT (2014a) Advanced treatment of antibiotic wastewater by nanofiltration: membrane selection and operation optimization. Desalin Water Treat 52(40-42):7575-7585

Wang JX, Wei YS, Li K, Cheng YT, Li MY, Xu JG (2014b) Fate of organic pollutants in a pilot-scale membrane bioreactornanofiltration membrane system at high water yield in antibiotic wastewater treatment. Water Sci Technol 69(4):876-881

Wang P, Wang ZW, Wu Z, Zhou Q, Yang D (2010) Effect of hypochlorite cleaning on the physiochemical characteristics of polyvinylidene fluoride membranes. Chem Eng J 162(3):1050-1056

Wang ZW, Wu ZC, Tang SJ (2009) Extracellular polymeric substances (EPS) properties and their effects on membrane fouling in a submerged membrane bioreactor. Water Res 43(9):2504-2512 
Xiao P, Xiao F, Wang DS, Qin T, He SP (2012) Investigation of organic foulants behavior on hollow-fiber UF membranes in a drinking water treatment plant. Sep Purif Technol 95:109-117

Xing ZP, Sun DZ (2009) Treatment of antibiotic fermentation wastewater by combined polyferric sulfate coagulation, Fenton and sedimentation process. J Hazard Mater 168(2-3):1264-1268
Xu P, Drewes JE, Kim TU, Bellona C, Amy G (2006) Effect of membrane fouling on transport of organic contaminants in NF/RO membrane applications. J Membr Sci 279(1-2):165-175

Zazouli MA, Nasseri S, Ulbricht M (2010) Fouling effects of humic and alginic acids in nanofiltration and influence of solution composition. Desalination 250(2):688-692 